\title{
BEHAVIORAL TRAINING IN SOCIAL WORK: AN UPDATE AND A PROGRAM DESCRIPTION
}

\author{
BRUCE A. THYER and DENISE BRONSON \\ The University of Michigan, \\ Doctoral Program in Social Work and Social Science
}

\begin{abstract}
Summary - The growth of behavior therapy during the past two decades has had a significant impact upon the education and training of professional social workers. Behavioral approaches are now well represented in the practice of clinical social work, and this trend is seen as likely to continue to expand. A description is provided of the behavioral training and research opportunities found at the masters and doctoral level in the School of Social Work at The University of Michigan.
\end{abstract}

Historically, the profession of social work has had a focus upon the social and environmental determinants of client behavior (Richmond, 1922). This has rendered behavioral approaches to individual and community intervention particularly appropriate for incorporation into social work educational and practice activities. A major impetus to the application of behavioral techniques to social work occurred in 1967, when the Council on Social Work Education established a task force investigating the relevance of socio-behavioral procedures to the field of social work. This resulted in an edited text by Thomas (1967) which reviewed state of-the-art technology of behavioral procedures in the areas of individual and group therapy, community change and administrative practice. Since that initial task force, behavioral procedures have expanded to the point where they now form one of the major schools of social work theory and practice (Thomas, 1970, 1973).

The Directory of Graduate Study in Behavior Therapy (Barlow, 1978) found 15 masters and doctoral social work programs whose behavior therapy training opportunities met the criteria which justified inclusion into the Directory. This represents a degree of growth which seems proportional to the expansion of behavior therapy training opportunities seen in the allied professions of clinical/counseling psychology and psychiatry. Social workers have been involved in the conduct of behavioral research and therapy since the earliest years of the field and are well represented in the rosters of behavioral organizations.

In recent years, numerous social work textbooks have been published which present the application of behavioral procedures to various fields of practice (Jehu et al., 1972; Thomas, 1974; Arkava, 1974; Schwartz and Goldiamond, 1975; Fischer and Gochros, 1975; Rose, 1977; Fischer, 1978; Wodarski and Bagarozzi, 1979; Jayaratne and Levy, 1979), and the increase in the sophistication and comprehensiveness of these texts has paralleled that seen in the broader field of behavior therapy. In addition to finding many applications in practice settings, behavioral theory is having a significant impact on the content of graduate training curricula (Clark and Comanor, 1973), and behavior therapy procedures are now disseminated through social work continuing education programs and in-service training institutes (Thomas, Etcheverry and Keller, 1975). The influence of behavioral 
techniques is also found on the teaching methods used in professional schools of social work (Peterson, 1977).

Previous articles (Jehu, 1970; Thomas, 1969; Graham, 1971) have discussed the role of the clinical social worker in behavior therapy and this issue will not be reviewed here. However, the facts that the 80,000 member strong National Association of Social Workers represents the largest source of mental health care personpower in the nation (Corman, 1980), and that clinical social workers provide more mental health care in the public sector than clinical psychologists and psychiatrists combined, (NIMH, 1971) point to the significant contribution which social work makes in the mental health care field and to the salience of behavior al training in social work graduate education.

Shorkey (1973) has described an example of a masters level behavioral training curriculum leading to the Master of Social Work degree, but the growth of the field since that article justifies an additional review. The remainder of this article describes the behavioral training and research opportunities at the School of Social Work at The University of Michigan.

\section{THE PROGRAM AT THE UNIVERSITY OF MICHIGAN}

The School of Social Work at The University of Michigan offers both masters and doctoral level training for students interested in behavioral approaches to individual and community intervention. The masters degree curriculum, leading to the degree of Master of Social Work (M.S.W.), affords the student a great deal of diversity by offering specializations in interpersonal practice, community organization, social welfare administration, social policy and planning, and social program evaluation. The interpersonal practice specialization is further subdivided into second year concentrations which allows the student to look more closely at practice areas that are especially interesting to $\mathrm{him} / \mathrm{her}$. The specializations include interpersonal practice from a clinical casework framework, and interpersonal practice with groups and families, among others.

One such concentration available to the masters level student is interpersonal practice from a behavior framework. The first course that students take that is particularly relevant to this sequence is "Principles of Behavior Modification I", which is required of all the interpersonal practice students and covers basic learning theory, behavioral concepts and terminology. The objective of this course is to introduce the student to the behavioral approach to treatment in general, and although examples of applications are presented to convey these concepts, the emphasis is not on teaching the student treatment techniques, but rather on providing a sound background in learning theory and empirical research findings relevant to behavior change. Students who concentrate in interpersonal practice from a behavioral framework are required to take "Principles of Behavior Modification II', a course which is also available to other students not in the behavioral sequence who wish to look more closely at specific applications of behavioral research and procedures. This course covers a variety of intervention strategies for each of several clinical problem areas, along with the existing empirical data on the effectiveness and indications for use of each approach. Behavioral case management methods are reviewed to provide a general framework for discussing more specific interventions in the areas of individual treatment, marital and family therapy, and child management problems. The emphasis of the course is primarily on social work practice in open service settings, although some attention is given to working with institutionalized clients as well as to macrolevel applications.

Implementation strategies for behavioral interventions in a clinical setting are reserved for the two non-sequential methods courses required of students in the behavioral concentration and open to others on an elective basis. "Behavioral Methods with Adults" focuses specifically on 
behavioral approaches to clinical problems such as depression, phobias, psychotic disorders, social skill deficits, lack of assertiveness, etc. The second methods course available, "Behavioral Methods with Families and Children", deals with assessment and treatment strategies related to marital, familial and child management difficulties. As their titles imply, these two methods courses offer specific "how to" information on the implementation of behavioral interventions in a clinical setting.

In addition to these behavioral concentration courses, students are also exposed to singlesubject research methodology in "Research in Interpersonal Influence". Several other nonconcentration courses also offer opportunities to focus on behavioral treatment and include substantial behavioral course content, as do the numerous elective offerings.

Students in the M.S.W. program are required to spend two full days per week of each semester of the two year program in a supervised ficld placement. Every attempt is made to coordinate student interests with the available placement opportunities and a number of behaviorally oriented sites are available. Students concentrating their studies in the behavioral area have spent at least one year of their field placement experience in one of the agencies which specifically request behavioral students. Field placement training is provided in family service agencies, community mental health centers, schools, institutions for the developmentally disabled and in children's services. These agencies offer a range of services which allows the student to gain experience using behavioral methods in a variety of problem areas and in a diversity of settings.

The doctoral program offers a Ph.D. in Social Work and Social Science, with incoming students indicating which of the social sciences they wish to study. Depending on their preference, students will complete departmental requirements in either psychology, sociology, political science or economics as well as the requirements of the School of Social Work. Students pursuing behavioral studies usually choose to affiliate with the psychology department. Following completion of the M.S.W., required of all students earning the Ph.D. in Social Work and Social Science, the student in the joint Social Work/Psychology program is required to complete at least $23 \mathrm{hr}$ of formal coursework in psychology, including a year of statistics and research methodology, and at least $12 \mathrm{hr}$ of doctoral level social work courses. Following completion of the coursework requirements, students complete preliminary examinations in both social work and psychology and subsequently engage in dissertation research focused on applying behavioral science from psychology to relevant practice areas in the field of social work.

Within the Department of Psychology, students in the joint program are able to fashion for themselves a package of courses to meet their specific research interests and needs, an individualization made possible by the vast number of opportunities and resources available at the University. More specifically, the psychology department offers courses in clinical, community, experimental and social psychology as well as in psychobiology, many of which are pertinent to behavioral training. In addition to the formal coursework available, the student can take advantage of opportunities to participate in ongoing research projects being conducted by faculty members, teach behavioral courses in both the psychology department and the School of Social Work, or serve as an outside consultant on other projects or settings where behavioral expertise is needed.

In the School of Social Work, several doctoral level courses focusing on behavioral theory and methodology are available. Although the specific content of the course may vary depending on the instructor, some of the courses which are regularly offered and address behavioral principles and methods include "Empirical and Theoretical Foundations of Behavior Change", "Principals and Techniques of Behavioral Intervention", "Principles and Procedures of Individual Change", "Intervention and Change Approaches to Marital and Family 
Treatment", "Assessment Procedures in Interpersonal Practice", "Special Seminars" and "Directed Readings".

Students in the doctoral program are also required to complete the equivalent of a 4 month full time research or utilization internship which requires working closely with a faculty member either in the School of Social Work or the Department of Psychology on a topic of mutual interest, and involves participation in ongoing research projects. The student's focus in one of these projects may be upon the conceptualization of a theoretical problem, the development and utilization of innovative methodological proccdurcs, or on engaging in more traditional experimental or applied research. For students who choose not to participate in a research internship, the utilization internship provides training and experience in applying a systematic body of behavioral science knowledge to a specific social work practice area. The student is expected to define a problem area, identify and assess sources of knowledge related to the problem, develop operational intervention principles from this knowledge, and assess the actual or anticipated effects of the intervention principles. As with the research internship, students can use this requirement or focus their attention on a behaviorally relevant area of interest.

A final opportunity for behavioral training and research experience is provided through the dissertation experience, a requirement which is similar in substance to that of other doctoral programs in psychology or social work, with the exception that the focus is upon the integration of psychological knowledge into various fields of practice in social welfare, a focus with obvious implications regarding the integration of behavioral methodology into social work.

In summary, the graduate training opportunities available in social work offer the interested student the opportunity to pursue both masters and doctoral level studies in behavioral therapy and research. Graduates of the doctoral program typically find positions in academia, being employed in both undergraduate and graduate education in schools of social work and/or in departments of psychology, and pursue various areas of behavioral research. Masters level social workers are typically employed in clinical settings, putting into practice the training in behavioral interventions they have received. Behavioral training has exerted a significant impact upon the provision of social work services to the extent that a recent survey by Jayaratne (1978) found that behavioral theory was a preferred theoretical orientation for approximately a third of all clinical social workers now in practice, a proportion deemed likely to grow as the behavioral training opportunities in social work education continue to expand.

\section{REFERENCES}

Arkava M. L. (1974) Behavior Modification: A Procedural Guide for Social Workers. The University of Montana Press, Missoula, Montana.

Barlow D. (Ed.) (1978) Directory of Graduate Study in Behavior Therapy. Association for Advancement of Behavior Therapy, New York.

Clark F. and Comanor A. (1973) Implications of the sociobehavioral framework for social work education, Soc. Worker 41, 291-303.

Corman J. (1980) Corman pays social work tribute, $N A S W$ News 25 (5), 2.

Fischer J. (1978) Effective Casework Practice: An Eclectic Approach. McGraw Hill, New York.

Fischer J. and Gochros H. (1975) Planned Behavior Change: Behavior Modification in Social Work. Free Press, New York.

Graham P. (1971) Some aspects of the relationship of social work to behavior therapy, Br. J. Soc: Work 1, 197-208.

Jayaratne S. (1978) A study of clinical eclecticism, Soc. Ser. Rev. 52,621-631.

Jayaratne S. and Levy R. (1979) Empirical Clinical Practice. Columbia University Press, New York.

Jehu D. (1970) The role of social workers in behavior therapy, J. Behav. Ther. \& Exp. Psychiat. 1, 17-28.

Jehu D., Hardiker P., Yelloly M. and Shaw M. (1972) Behavior Modification in Social Work. John Wiley, New York.

National Institute of Mental Health (1971) Preliminary Data on Staffing Patterns in Federally Funded Community Mental Health Centers. Survey and Reports Section-PPEB, Rockville, Maryland.

Peterson C. (1977) The consequation exercise: A tool for teaching behavior modification to social work students. I. Educ. Soc. Work 13, 96-103.

Richmond M. (1922) What is Social Casework? Russell Sage, New York. 
Rose S. (1977) Group Therapy: A Behavioral Approach. Prentice Hall, New York.

Schwartz A. and Goldiamond I. (1975) Social Casework: A Behavioral Approach. Columbia University Press, New York.

Shorkey C. (1973) Behavior therapy training in social work education, J. Behav. Ther. \& Exp. Psychiat. 4, 195196.

Thomas E. (Ed.) (1967) The Socio-Behavioral Approach and Applications to Social Work. Council on Social Work Education, New York.

Thomas E. (1969) Contributions of the socio-behavioral approach to interpersonal helping in social work, $\mathrm{Br}$. J. Psychiat. Soc. Work 10, 61-69.

Thomas E. (1970) Behavioral modification and casework.
In Theories of Social Casework (Ed. by Roberts R. and Nee R.) University of Chicago Press, Chicago, Illinois.

Thomas E. (Ed.) (1974) Behavior Modification Procedure: A Sourcebook. Aldine Publishing Company, Chicago, Illinois.

Thomas E. (1973) Social casework and social group work: The behavioral modification approach. In Encyclopedia of Social Work (Ed. by Morris R.). National Association of Social Workers, New York.

Thomas F., Ftcheverry R. and Keller R. (1975) Repertoires of behavioral and nonbehavioral treatment methods used in social work, Soc. Ser. Rev. 49, 107-114.

Wodarski J. and Bagarozzi D. (1979) Behavioral Social Work. Human Sciences Press, New York. 